\title{
Thionin-like peptide from Capsicum annuum fruits: mechanism of action and synergism with fluconazole against Candida species
}

\author{
Gabriel B. Taveira', André O. Carvalho' ${ }^{1}$, Rosana Rodrigues², Fernanda G. Trindade ${ }^{3}$, Maura Da Cunha ${ }^{3}$ \\ and Valdirene M. Gomes ${ }^{1 *}$
}

\begin{abstract}
Background: Thionins are a family of plant antimicrobial peptides (AMPs), which participate in plant defense system against pathogens. Here we describe some aspects of the CaThi thionin-like action mechanism, previously isolated from Capsicum annuum fruits. Thionin-like peptide was submitted to antimicrobial activity assays against Candida species for $\mathrm{IC}_{50}$ determination and synergism with fluconazole evaluation. Viability and plasma membrane permeabilization assays, induction of intracellular ROS production analysis and CaThi localization in yeast cells were also investigated.

Results: CaThi had strong antimicrobial activity against six tested pathogenic Candida species, with $\mathrm{IC}_{50}$ ranging from 10 to $40 \mu \mathrm{g} \cdot \mathrm{mL}^{-1}$. CaThi antimicrobial activity on Candida species was candidacidal. Moreover, CaThi caused plasma membrane permeabilization in all yeasts tested and induces oxidative stresses only in Candida tropicalis. CaThi was intracellularly localized in C. albicans and C. tropicalis, however localized in nuclei in C. tropicalis, suggesting a possible nuclear target. CaThi performed synergistically with fluconazole inhibiting all tested yeasts, reaching $100 \%$ inhibition in C. parapsilosis. The inhibiting concentrations for the synergic pair ranged from 1.3 to 4.0 times below $\mathrm{CaThi} I \mathrm{C}_{50}$ and from zero to 2.0 times below fluconazole $\mathrm{IC}_{50}$.
\end{abstract}

Conclusion: The results reported herein may ultimately contribute to future efforts aiming to employ this plantderived AMP as a new therapeutic substance against yeasts.

Keywords: Antimicrobial peptides, Thionin, Synergistic activity, Fluconazole, Candida

\section{Background}

Currently, a significant global public health threat is the emergence of pathogenic bacteria, fungi, and yeasts that are resistant to multiple antimicrobial agents. Indeed, few or no effective chemotherapies are available for infections caused by some of these resistant microorganisms $[1,2]$.

Alternatives to chemotherapies include antimicrobial peptides (AMPs), small molecules produced by all living organisms, which have gained considerable attention

\footnotetext{
* Correspondence: valmg@uenf.br

'Laboratório de Fisiologia e Bioquímica de Microrganismos, Centro de Biociências e Biotecnologia, Universidade Estadual do Norte Fluminense, Campos dos Goytacazes 28013-602, RJ, Brazil

Full list of author information is available at the end of the article
}

because of their potent antimicrobial activity against a broad range of microbes, including viruses, bacteria, protozoa, and fungi $[3,4]$. Moreover, some kill microorganisms rapidly, are able to synergize with other AMPs and clinical antibiotics, have low toxicity to mammalian cells, and exert their microbial inhibitory activity at low concentrations. These molecules have multiple targets in the plasma membrane and also in intracellular components, which is thought to make an increase in microbial resistance more difficult $[2,5]$.

Promising AMPs include plant-derived thionins, a family of basic, low molecular weight $(\sim 5 \mathrm{kDa})$, cysteinerich peptides. Various family members have high sequence similarity and structure [6-8]. Many of them 
are toxic against yeasts, pathogenic fungi, Gram-positive and Gram-negative bacteria, protozoa, and insects [710]. Like other AMPS, thionins' antimicrobial activity relies on their interaction with phospholipids to cause membrane instability [10].

Infections caused by Candida species have increased substantially over the last 30 years due to the rise of AIDS, ageing population, numbers of immunocompromised patients and the extensive use of indwelling prosthetic devices [1, 11]. Candida albicans is the main cause of candidiasis, however, other Candida species such as C. tropicalis, C. parapsilosis, and C. glabrata are now frequently identified as human pathogens [11-13]. Antifungals, especially fluconazole (FLC), have been used with some success for the treatment of Candida infections; however, there are numerous reports on the emergence of strains resistant to azoles that overexpress multidrug efflux transporters $[14,15]$.

In a previous report [8], our research team isolated a plant-derived thionin, named $\mathrm{CaThi}$, with strong antimicrobial activity against two pathogenic Candida species, as well as Escherichia coli and Pseudomonas aeruginosa. FLC in combination with AMPs resulting in promising therapeutic results against important human pathogens, such as C. albicans and Cryptococcus neoformans, has been demonstrated [16, 17]. In this work we investigated whether the AMP CaThi could act synergistically with FLC. This synergistic strategy could result in a more efficient response against six Candida strains of clinical importance, avoiding the cytotoxic effects commonly exhibited by thionins against mammalian cells [10] by using low concentrations of this AMP. We were also interested in understanding the mechanism by which plant-derived thionins affect Candida species, which remains partially unknown [10]. These questions are addressed in the present study.

The results reported herein may ultimately contribute to future efforts aiming to develop this plant-derived AMP as a new therapeutic substance against these pathogenic Candida species as well as other yeast infections.

\section{Results}

\section{Determination of $\mathrm{IC}_{50}$ for $\mathrm{CaThi}$ and $\mathrm{FLC}$}

Initially we performed growth inhibition assays of six Candida species using different concentrations of FLC and thionin $\mathrm{Ca}$ Thi to determine the $\mathrm{IC}_{50}$ of these substances. The lowest $\mathrm{IC}_{50}$ for $\mathrm{FLC}$ was found for C. buinensis $\left(0.125 \mu \mathrm{g} \cdot \mathrm{mL}^{-1}\right)$ and the highest for C. pelliculosa $\left(5 \mu \mathrm{g} \cdot \mathrm{mL}^{-1}\right)$. In the case of CaThi, $10 \mu \mathrm{g} \cdot \mathrm{mL}^{-1}$ was sufficient to cause $50 \%$ inhibition of growth of C. albicans, C. tropicalis, C. parapsilosis, and C. buinensis but $40 \mu \mathrm{g} . \mathrm{mL}^{-1}$ was necessary to achieve $\mathrm{IC}_{50}$ for C. pelliculosa. Thus, higher concentrations of both FLC and $\mathrm{Ca}$ Thi were needed to affect the growth of C. pelliculosa.
Moreover, although the antimicrobial activity of $\mathrm{CaThi}$ against Candida species is indeed relevant, our data showed it to be lower than that observed for FLC (Table 1).

\section{Viability assay}

$\mathrm{Ca}$ Thi induced viability loss in all yeasts cells tested (Fig. 1a). The most susceptible species to $C a$ Thi were $C$. buinensis, C. parapsilosis and C. albicans with 99.2, 98.9 and $80.3 \%$ of viability loss, respectively, and the less susceptible was C. tropicalis with $47.9 \%$ of viability loss (Fig. 1b). These results indicated that inhibitory effect of CaThi was candidacidal.

\section{Plasma membrane permeabilization}

Candida species cells were tested to determine the membrane permeabilization by Sytox green dye. All yeasts showed Sytox green fluorescence when grown for $24 \mathrm{~h}$ in the presence of $\mathrm{CaThi} \mathrm{IC}_{50}$. As with other AMPs, it is likely that $\mathrm{CaThi}$ acts on the plasma membrane of these Candida species, compromising it structurally and allowing the permeabilization of the labeling dye (Fig. 2). The membrane permeabilization percentage of the treated yeasts with $\mathrm{Ca}$ Thi was assessed (Table 2). A higher number of C. albicans and C. pelliculosa cells presented higher Sytox green fluorescence percentage, suggesting that $\mathrm{CaThi}$ is more effective at permeabilizing the membrane of these cells than the other Candida species analyzed.

\section{ROS induction assay}

Endogenous production of ROS was analyzed by incubating the yeasts for $24 \mathrm{~h}$ with $\mathrm{CaThi} \mathrm{IC}_{50}$. Increased ROS production was observed only in $C$. tropicalis (Fig. 3), suggesting that a CaThi-induced increase in oxidative stress may underlie the growth inhibitory effect on this yeast. Nevertheless, oxidative stresses were not detected for other Candida species, implicating that we could not associate the $\mathrm{CaThi}$ role and ROS production with growth inhibition of Candida, at least for the concentrations tested.

Table $1 \mathrm{IC}_{50}^{\mathrm{a}}\left(\mu \mathrm{g} \cdot \mathrm{mL}^{-1}\right)$ of fluconazole and CaThi in different species of Candida respectively

\begin{tabular}{lcc}
\hline Yeasts & Fluconazole & CaThi \\
\hline Candida albicans (CE022) & 1.0 & 10.0 \\
Candida tropicalis (CE017) & 1.0 & 10.0 \\
Candida parapsilosis (CE002) & 0.5 & 10.0 \\
Candida pelliculosa (3974) & 5.0 & 40.0 \\
Candida buinensis (3982) & 0.125 & 10.0 \\
Candida mogii (4674) & 2.5 & 20.0 \\
\hline
\end{tabular}

${ }^{a}$ represents the concentration of a drug that is required for $50 \%$ inhibition in vitro 


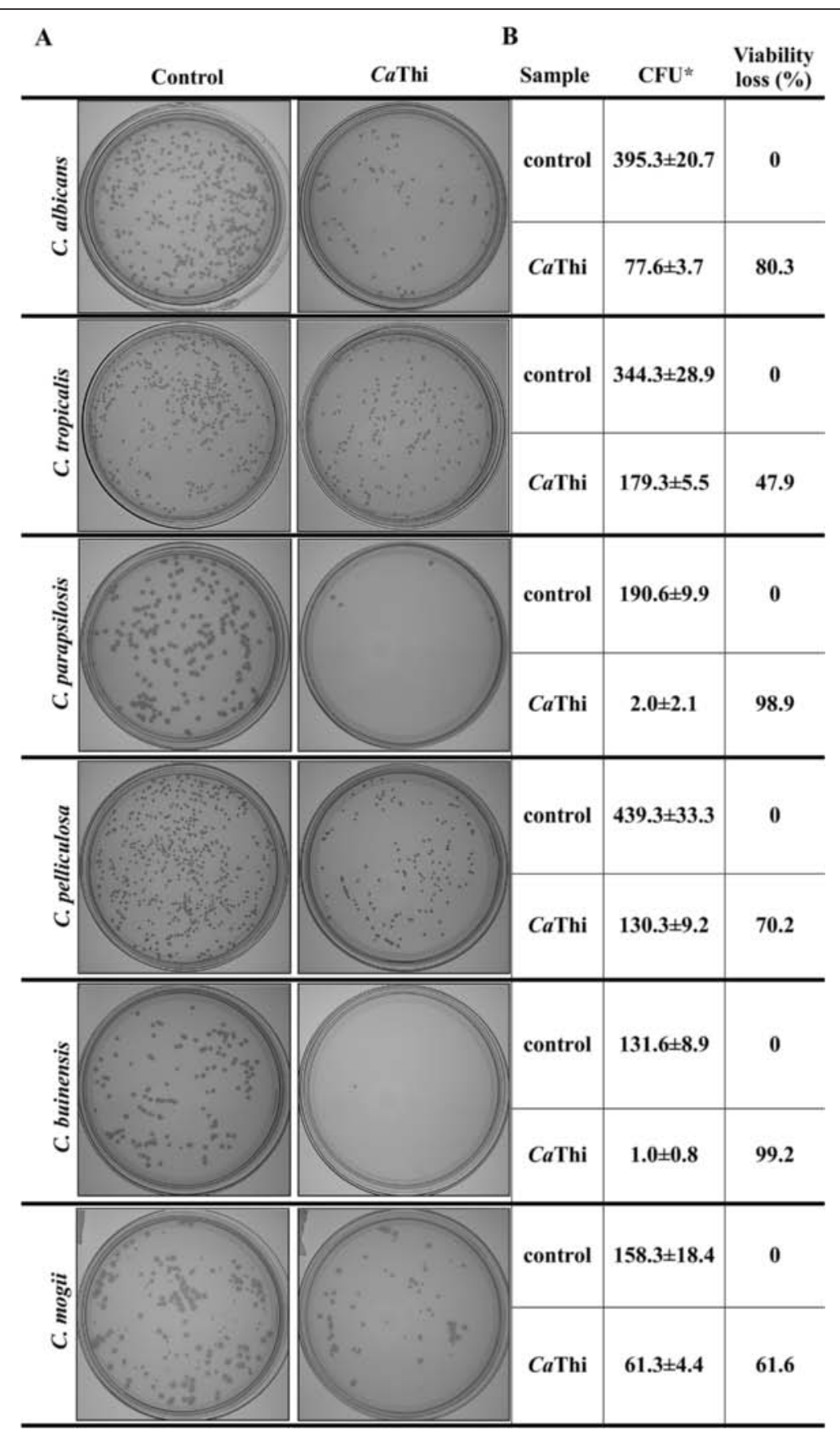

Fig. 1 Cell viability loss. a Photographs of the Petri dishes showing the viability of yeasts cells after the treatment with $I C_{50}$ CaThi for 24 h. b The table shows the percentage of viability loss of yeasts cells after the treatment with $\mathrm{IC}_{50}$ CaThi for $24 \mathrm{~h}$. CFU = Colony forming unit. $\left(^{*}\right)$ Indicates significance by the $T$ test $(P<0.05)$ among the experiments and their respective controls. The experiments were carried out in triplicate

\section{Localization of CaThi in yeast cells}

We also investigated whether CaThi was actually internalized in C. albicans and C. tropicalis cells. These yeasts were chosen because they are known to be the most opportunistic pathogens among Candida species. Another important point is that $C$. tropicalis was the only yeast that presented membrane permeabilization and induction of ROS by $\mathrm{CaThi}$ in this work. To perform the test, we used $10 \mu \mathrm{g} \cdot \mathrm{mL}^{-1}$ of
FITC-tagged $\mathrm{CaThi}$ to search for intracellular signal fluorescence. We also treated the cells with DAPI for nuclei labeling. Intracellular signal fluorescence of $\mathrm{CaThi}$-FITC was observed in both of these Candida species. However, while CaThi-FITC labeling of $C$. tropicalis produced a specific and intense spot of fluorescence inside the cells, $C$. albicans cells showed a more diffuse fluorescence. Overlapping of these $\mathrm{CaThi}$-FITC images with DAPI nuclei labeling 


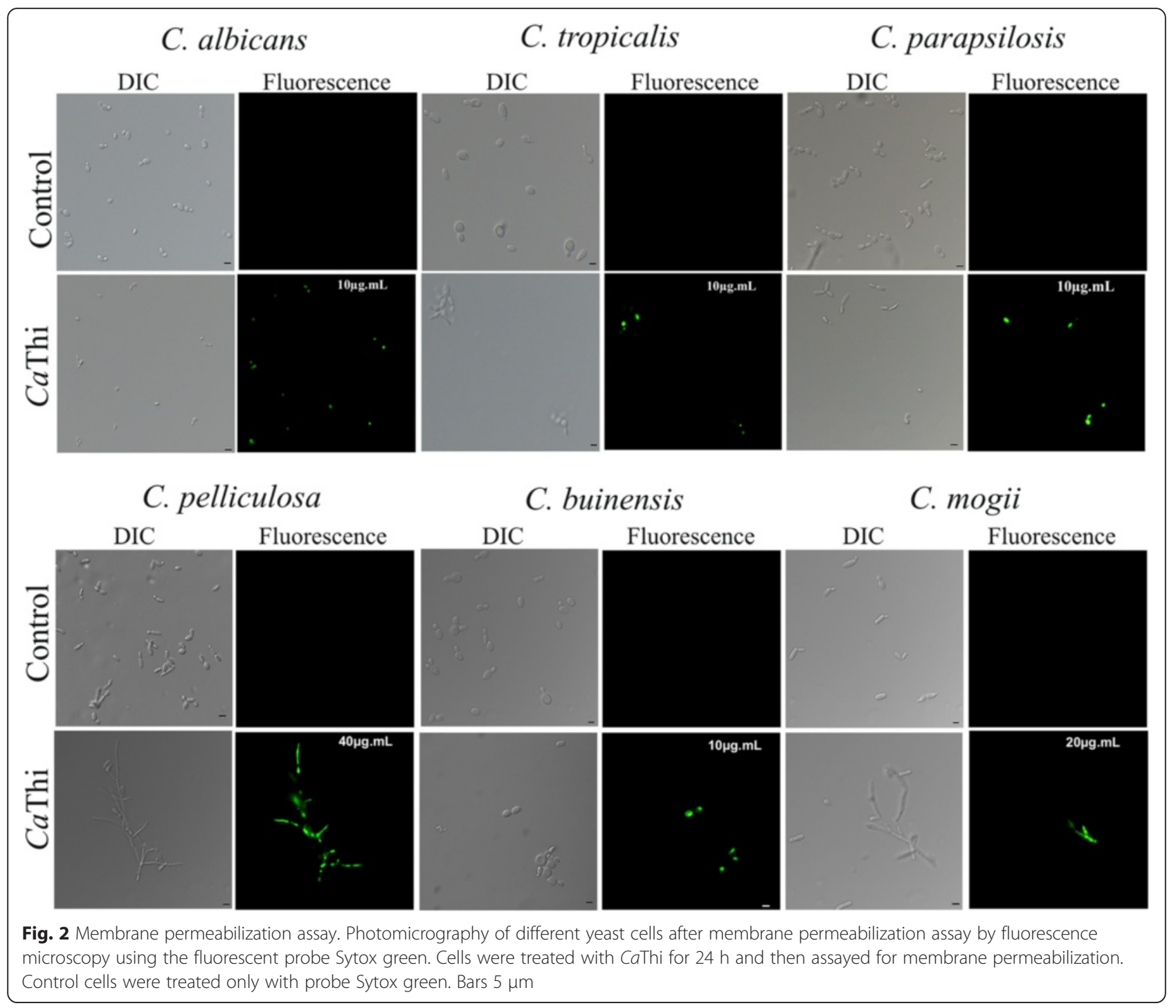

indicated a co-localization of these fluorescent signals in C. tropicalis but not in C. albicans cells (Fig. 4). These data suggest that, at least for C. tropicalis, $\mathrm{CaThi}$ may have an intracellular target, possibly located in the nucleus.

\section{Synergism assay}

Given the increase in Candida infections, particularly among immunocompromised patients, searches for antifungal therapeutic alternatives are warranted. This concern and the aforementioned data prompted us to investigate whether FLC and $\mathrm{CaThi}$ could act synergistically to improve therapeutic results against Candida species. The combination of FLC and CaThi showed an increase in inhibitory activity of all of the Candida species tested, suggestive of synergistic activity (Table 3). Interestingly, although $C$. pelliculosa had the highest $\mathrm{IC}_{50}$ for both substances, when we combined FLC at one-fold below its $\mathrm{IC}_{50}$ and $\mathrm{CaThi}$ at threefold below its $\mathrm{IC}_{50}$, we observed $57 \%$ increase in growth inhibition of this yeast. Similarly, in C. parapsilosis cells, when $\mathrm{IC}_{50}$ FLC was combined with $\mathrm{Ca}$ Thi threefold below its $\mathrm{IC}_{50}$, we obtained $100 \%$ growth inhibition of this yeast. Combined use of FLC and CaThi also strongly inhibited (96\%) C. tropicalis, although when used separately the inhibition achieved with these substances did not reach $12 \%$. Taken together, these data suggest that in combination FLC and CaThi could have an important synergistic action resulting in very effective control of Candida species.

\section{Morphological alterations of CaThi and FLC plus CaThi on yeast growth}

Investigation regarding the possible morphological alterations in yeast cells grown in the presence of FLC, $\mathrm{CaThi}$, or a combination of both substances after the inhibition assays (Fig. 5a) was performed. Optical 
Table 2 Fluorescent cell percentage of yeasts treated with $\mathrm{CaThi}^{\mathrm{a}}$

\begin{tabular}{|c|c|c|c|c|}
\hline Yeasts species & Sample & Cell number viewed in DIC & Cell number viewed in fluorescence & $\%$ of fluorescence cells ${ }^{b}$ \\
\hline \multirow[t]{2}{*}{ C. albicans } & control & $62.0 \pm 9.3$ & $0.6 \pm 0.8$ & 0.9 \\
\hline & CaThi & $20.0 \pm 5.0$ & $16.6 \pm 5.3$ & 83.0 \\
\hline \multirow[t]{2}{*}{ C. tropicalis } & control & $41.2 \pm 4.2$ & $0.8 \pm 1.3$ & 1.9 \\
\hline & CaThi & $9.8 \pm 4.9$ & $4.8 \pm 4.6$ & 48.9 \\
\hline \multirow[t]{2}{*}{ C. parapsilosis } & control & $79.2 \pm 12.1$ & 0 & 0 \\
\hline & CaThi & $18.2 \pm 5.4$ & $6.2 \pm 1.4$ & 34.0 \\
\hline \multirow[t]{2}{*}{ C. pelliculosa } & control & $23.8 \pm 3.5$ & 0 & 0 \\
\hline & CaThi & $7.2 \pm 1.9$ & $6.6 \pm 2.3$ & 91.6 \\
\hline \multirow[t]{2}{*}{ C. buinensis } & control & $43.6 \pm 9.0$ & $0.8 \pm 1.3$ & 1.8 \\
\hline & CaThi & $13.6 \pm 6.2$ & $6.2 \pm 1.3$ & 45.5 \\
\hline \multirow[t]{2}{*}{ C. mogii } & control & $18.6 \pm 3.2$ & $0.6 \pm 0.8$ & 3.2 \\
\hline & CaThi & $8.6 \pm 2.0$ & $4.4 \pm 2.7$ & 51.1 \\
\hline
\end{tabular}

a Cells number determination in five random fields of the DIC and fluorescence views of the samples obtained from Plasma membrane permeabilization assay. The total cell number in DIC of each yeast (in control and test) was assumed as $100 \%$

${ }^{\mathrm{b}}$ Indicates significance by the $T$ test $(P<0.05)$ among the experiments and their respective controls

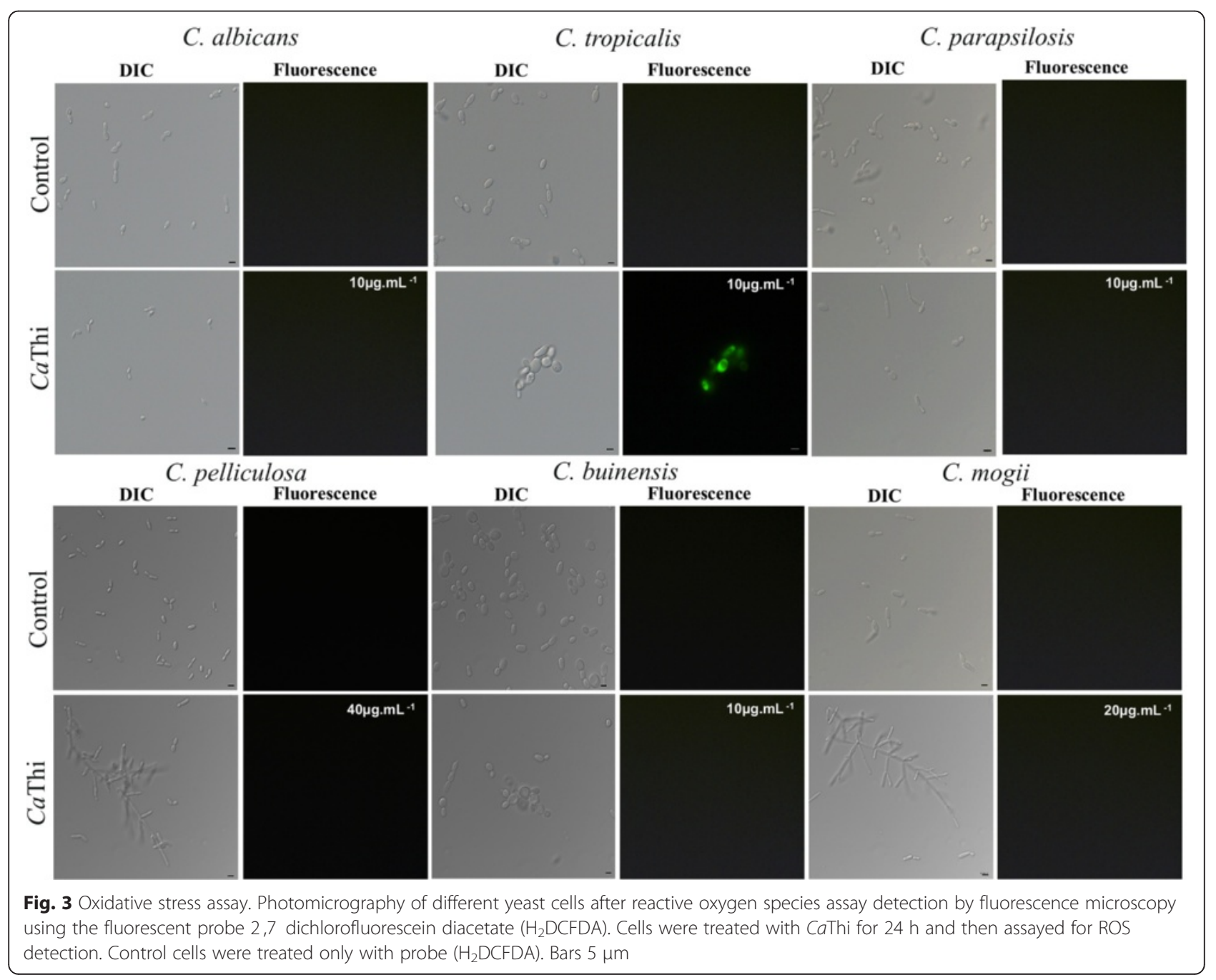




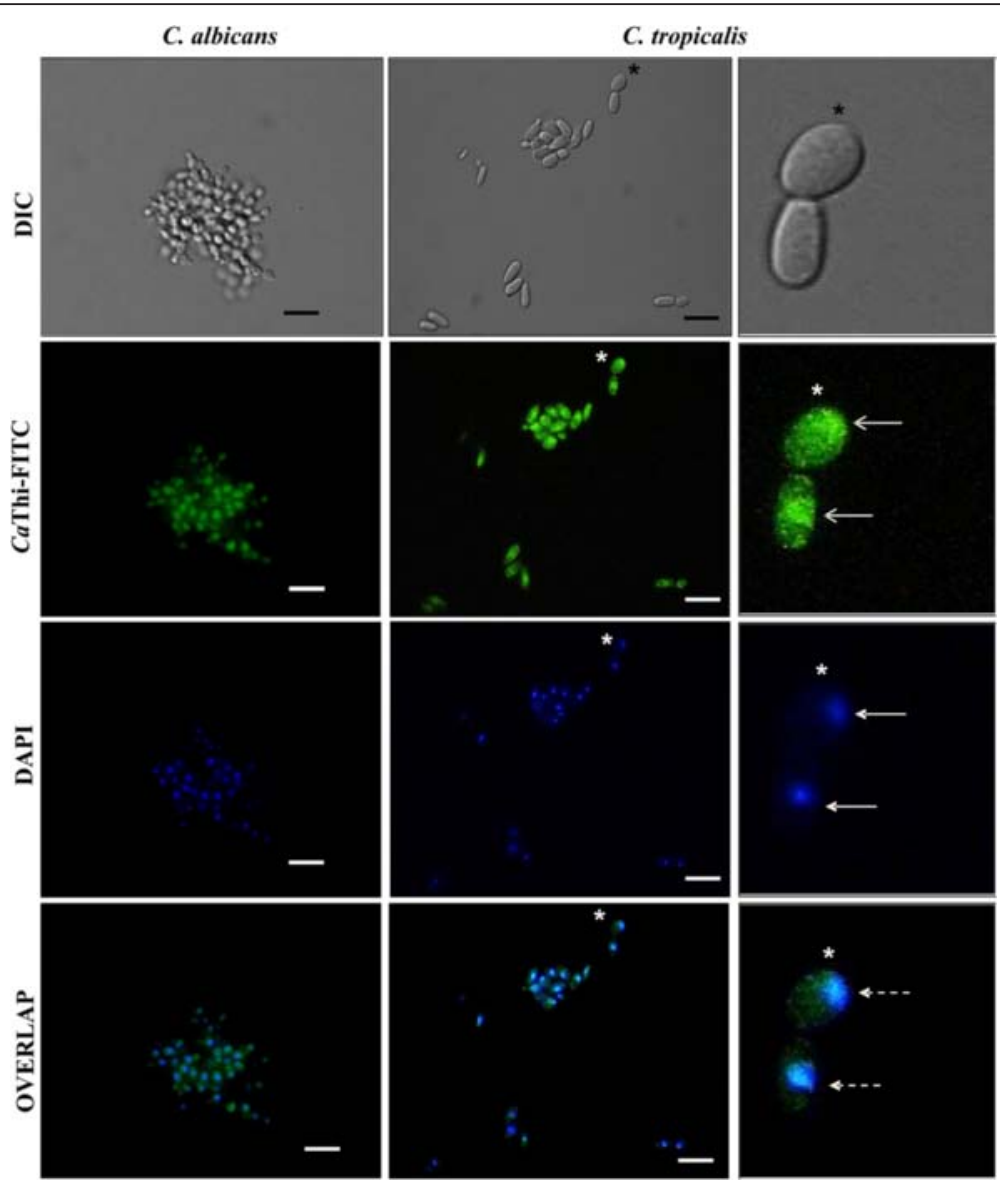

Fig. 4 Localization of CaThi in yeast cells. Photomicrography of Candida albicans and Candida tropicalis cells incubated for $24 \mathrm{~h} \mathrm{with} 10 \mu \mathrm{g} . \mathrm{mL}^{-1}$ CaThi-FITC (green fluorescence, open arrows) by fluorescence microscopy. Nuclei were visualized by 4,6-diamidino-2-phenylindole dihydrochloride (DAPI) after the CaThi-FITC incubation period (blue fluorescence, filled arrows). Overlap of the DAPI and FITC images (dotted arrows). Bars $20 \mu \mathrm{m} .\left(^{*}\right)$ Indicates the position of digital enlargement

Table 3 Inhibition percentage of yeast species treated with CaThi and FLC alone and in combination showing synergism effect in vitro

\begin{tabular}{|c|c|c|c|c|}
\hline Yeasts species & Sample & Concentration $\left(\mu \mathrm{g} \cdot \mathrm{mL}^{-1}\right)^{a}$ & Inhibition (\%) & Combination inhibition (\%) $(\mathrm{CaThi}+\mathrm{FLC})^{\mathrm{b}}$ \\
\hline \multirow[t]{2}{*}{ C. albicans } & CaThi & 3.5 & 2.93 & 77.5 \\
\hline & FLC & 0.5 & 24.48 & \\
\hline \multirow[t]{2}{*}{ C. tropicalis } & CaThi & 3.5 & 0 & 96.26 \\
\hline & FLC & 0.5 & 11.55 & \\
\hline \multirow[t]{2}{*}{ C. parapsilosis } & CaThi & 3.5 & 4.0 & 100.0 \\
\hline & FLC & 0.5 & 50 & \\
\hline \multirow[t]{2}{*}{ C. pelliculosa } & CaThi & 15.0 & 2.63 & 57.45 \\
\hline & FLC & 2.5 & 7.8 & \\
\hline \multirow[t]{2}{*}{ C. buinensis } & CaThi & 5.0 & 19.0 & 67.01 \\
\hline & FLC & 0.06 & 5.45 & \\
\hline \multirow[t]{2}{*}{ C. mogii } & CaThi & 10.0 & 17.19 & 61.05 \\
\hline & FLC & 1.0 & 22.80 & \\
\hline
\end{tabular}

${ }^{a} \mathrm{CaThi}$ concentrations ranging 1.3 to 4.0 times below it IC 50 and $\mathrm{FLC}$ concentrations 2.0 times below it IC 50 or at it IC

${ }^{b}$ Indicates significance by the ANOVA test $(P<0.05)$ which were calculated by the absorbance values of synergism among the experiments and their respective controls 


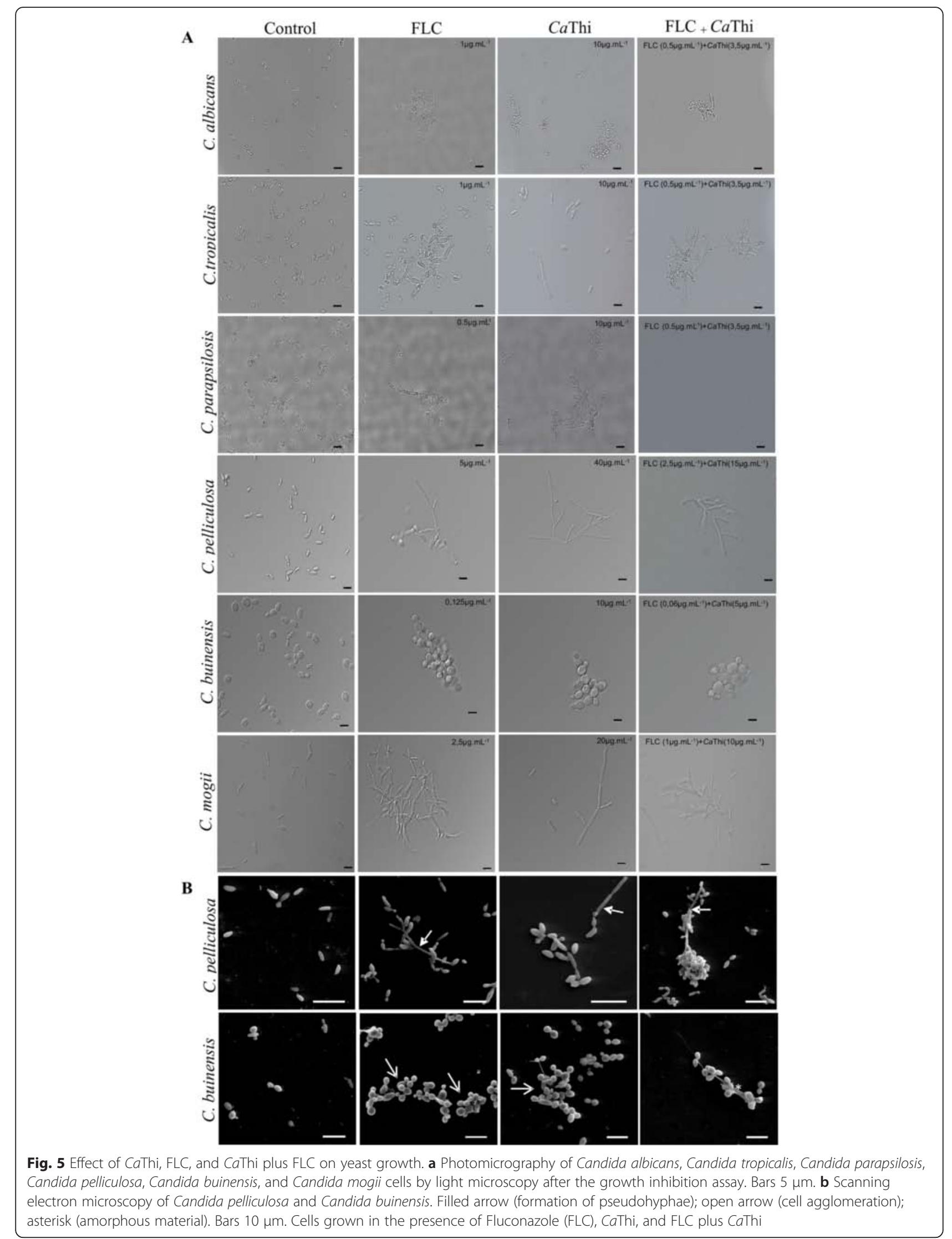


microscopy analysis revealed that FLC, $\mathrm{CaThi}$, and the combined treatment caused changes in the morphology of cells of Candida species. C. tropicalis, C. parapsilosis, C. pelliculosa, and C. mogii exhibited an apparent difficulty in releasing buds thus leading to the formation of pseudohyphae when grown in the presence of $\mathrm{CaThi}$. Moreover, in the presence of either substance, C. tropicalis cells presented hyper branching of pseudohyphae. For $C$. albicans and $C$. buinensis, an intense cellular agglomeration in all treatments was observed. Further, the combination of $\mathrm{CaThi}$ and FLC caused a shrunken appearance in $C$. albicans cells.

Scanning Electronic Microscopy (SEM) of C. pelliculosa reinforces the optical microscopy observations, corresponding to intense cell agglomeration and pseudohyphae formation in all treatments. For $C$. buinensis, all treatments showed intense cellular agglomeration and apparent difficulty in bud release, but not in the formation of pseudohyphae. For this yeast an amorphous material among cells in all treatments was also observed (Fig. 5b). These results show that $\mathrm{Ca}$ Thi is capable of causing morphological changes similar to FLC, an azole antifungal agent, commonly used in treatment of infections caused by Candida species. Importantly, we were able to demonstrate that the combination of these substances potentiates the therapeutic effects against these opportunistic species of Candida.

\section{Discussion}

Plant-derived thionins exhibit toxic effects against a wide range of plant pathogens including bacteria and fungi [18-21]. However, there is a gap regarding the mode of action of plant-derived thionins against human pathogens. Prompted by the considerable increase in the incidence of human infections by Candida species, we investigated the potential of $\mathrm{CaThi}$, a plant-derived thionin peptide, as a novel therapeutic drug against six Candida strains of clinical interest: C. albicans, C. tropicalis, C. parapsilosis, C. pelliculosa, C. buinensis, and C. mogii.

The growth inhibition assay was not done with RPMI 1640 medium, which is generally indicated by Clinical and Laboratory Standards Institute guidelines, because it has in its composition a large amount of inorganic salts and it is well known in the literature that the presence of salts, such as sodium chloride and magnesium sulfate, can decrease the inhibitory activity of antimicrobial peptides since it is necessary electrostatic approximation of the peptide with the membrane of microorganisms and the presence of salts disrupts this initial interaction [22-24]. Therefore, as explained above, our growth inhibition assay was done with Sabouraud broth which is a common used medium to growth of fungi, including Candida albicans.
Our growth inhibition assays of the six Candida species tested revealed that $10 \mu \mathrm{g} \cdot \mathrm{mL}^{-1}$ was $\mathrm{IC}_{50}$ for $C a \mathrm{Thi}$ to inhibit the growth of C. albicans, C. tropicalis, C. parapsilosis, and C. buinensis but $40 \mu \mathrm{g} \cdot \mathrm{mL}^{-1}$ was necessary to achieve $\mathrm{IC}_{50}$ for $C$. pelliculosa (Table 1 ), and this inhibitory effect was candidacidal inducing viability loss in all yeast cells tested (Fig. 1). Thi 2.1, a thionin from Arabidopsis thaliana, achieved $80 \%$ inhibition of $C$. albicans with $2.5 \mu$ g. $\mathrm{mL}^{-1}$ [25]. Although Thi 2.1 showed stronger antimicrobial activity against $C$. albicans than $C a$ Thi, these authors did not test it against non-albicans species. Thus, whether this thionin would affect other species with similar strength remains unknown.

Sytox green is a dye that only penetrates cells when the plasma membrane is structurally compromised. All yeast species tested showed Sytox green fluorescence (Fig. 2), however $\mathrm{CaThi}$ was more effective in plasma membrane permeabilization in $C$. albicans and $C$. pelliculosa (Table 2). Antimicrobial activity against the fungus Neurospora crassa by $\alpha$-Hodothionin, isolated from barley seeds, also occurs via a mechanism involving membrane permeabilization, resulting in the inward flux of $\mathrm{Ca}^{2+}$ and $\mathrm{K}^{+}$efflux and consequent potential membrane collapse [26]. Another plant-derived thionin isolated from Viscum album, named $\mathrm{VtA}_{3}$, interacts with the plasma membrane of the fungus Fusarium solani, causing its permeabilization and thus inhibiting the growth of this microorganism [27]. Indeed, several studies suggest that most of the biological effects of thionins result from the interaction of these peptides with the target cell membrane. Three mechanisms have been proposed: formation of an ion-selective channel; formation of patches or carpets of peptides; and loss of membrane phospholipids [10].

AMPs have been demonstrated to play a direct role in membrane permeabilization, causing a loss of membrane potential [28]. As cells depend on membrane potential to fulfill their physiological functions, its restoration is mandatory and demands cellular energy. One possible consequence of this process is ROS generation by activated mitochondria [29]. Therefore, we analyzed whether this primary membrane-permeabilizing event in Candida species induced by $\mathrm{CaThi}$ was followed by oxidative stress. Interestingly, CaThi only induced production of ROS in C. tropicalis (Fig. 3). We speculate that $\mathrm{Ca}$ Thi binds to a specific domain of the $C$. tropicalis membrane, which triggers the increase in oxidative stress response through ROS production. However, further studies are needed to establish this. Reports show that increase in ROS production by the target organisms is a recurring mode of action employed by thionins and other AMPs [27, 30, 31]. Indeed, increased death of the fungus Fusarium solani subjected to $\mathrm{VtA}_{3}$ was connected with boosted ROS production by these organisms 
[27]. More recently, a peptide similar to thionin isolated from the beetle Psacothea hilaris also provoked in increase in the levels of endogenous ROS in C. albicans [32]. Our study is the first to report increase in ROS production by a plant-derived thionin as an antimicrobial mechanism against a human pathogen, $C$. tropicalis. Therefore, CaThi seems to employ a sophisticated mechanism to inhibit the growth of this opportunistic yeast involving not only membrane permeabilization but also induction of oxidative stress response.

Some AMPs are able to enter the cell, after the initial cell membrane interaction [33, 34]. Accordingly, the next experiments were designed to analyze whether $C a$ Thi was able to actively enter $C$. albicans and C. tropicalis. In the approach used, FITC-tagged $\mathrm{CaThi}$ was monitored by fluorescence microscopy. Because CaThi entered C. albicans and C. tropicalis cells, we suggest that a possible intracellular target for this thionin might be part of a complex mechanism responsible for the death of Candida species. FITC-tagged CaThi overlapped with DAPI staining, indicating that, in C. tropicalis, this target is nuclear (Fig. 4). Giudici et al. [27] showed that $\mathrm{VtA}_{3}$ entered and accumulated in the fungus $F$. solani. These authors also demonstrated that this entry was related to the sphingolipid composition of the plasma membrane of this fungus. Our study is the first to show that a plant-derived thionin ( $\mathrm{CaThi}$ ) is able to enter human pathogens (C. albicans and C. tropicalis) and to suggest an intracellular target for it. Our work opens new perspectives regarding the antimicrobial mechanism of plant-derived thionins as it suggests that these peptides' toxicity may not be restricted to the plasma membrane.

The real mode of action of AMPs has not been fully elucidated, but much of the described AMPs to date target the plasma membrane of microorganisms causing pore formation and leading to imbalance in cellular homeostasis [33, 35]. However, some studies showed that not only is permeabilization the cause of a particular microorganism death, as they may have multiple targets [36] after the interaction with the membrane causing, for example, ROS induction [31, 37]; inhibition of protein synthesis [38, 39]; inhibition of mitochondrial activity $[40,41]$, and also may trigger signaling cascades that lead to apoptosis $[42,43]$. Thus it is difficult to identify the most important factor for the candidacidal effect of CaThi and is technically challenging to characterize the steps leading up to cell death, however evidence supports that all events described in the manuscript may have a crucial role in the death of the tested yeasts.

The continuous emergence of resistance of fungal strains to conventional antibiotics and antifungals, especially Candida species, has become an important medical issue and has spurred the demand for new therapeutic alternatives. This concern prompted us to investigate whether FLC and $\mathrm{CaThi}$ could act synergistically to improve therapeutic results against Candida species. Here we show that the combination of these two substances was effective against all Candida species tested (Table 3), causing drastic morphological changes in these cells (Fig. 5). Interestingly, we show that the inhibitory effect of this combination was more effective for C. albicans, C. parapsilosis, and C. tropicalis, which are the major yeast species recovered from infections in immunocompromised patients [13]. The azoles mode of action occurs by inhibition of the enzyme lanosterol 14 $\alpha$-demethylase, blocking ergosterol incorporation and leading to the accumulation of intermediate sterols. These intermediate sterols do not have the same configuration and physical properties of ergosterol, therefore they cause the plasma membrane to form with altered properties, changing in fluidity, permeability and impairing nutrient uptake, which ultimately lead to cell toxicity $[44,45]$. In regard to the synergistic effect of FLC and $\mathrm{CaThi}$, we hypothesize that permeabilization is firstly caused by $\mathrm{Ca}$ Thi (Fig. 2) facilitating the entrance of FLC into the cell cytoplasm, triggering structural alterations in the plasma membrane which feedback positively to the entrance of more CaThi and FLC. This entrance creates potential for toxic effects, which were experimentally observed in the lower $\mathrm{IC}_{50}$ used for both substances in the combinatory treatment (Table 3). Additionally, secondary toxicity effects were demonstrated, such as the induction of ROS to C. tropicalis, the CaThi presence in C. albicans cell cytoplasm and in C. tropicalis nuclei. These localizations suggest that $\mathrm{CaThi}$ may have cytoplasmic targets, where interference could consolidate the inhibitory effect. However, more studies are necessary to clearly unravel the antimicrobial mechanism of CaThi against Candida species as well as the mechanism of synergy between CaThi and FLC.

\section{Conclusions}

Investigating a plant-derived thionin mode of action against opportunistic human pathogenic yeasts is relevant and advisable, whereas most studies involving plant-derived thionins focus their effects against plant pathogenic microorganisms as experimental models. In this report, we demonstrated that $\mathrm{CaThi}$ has strong candidacidal activity against six pathogenic Candida species, and it works by permeabilizing the membrane and inducing oxidative stress response in these yeasts. Additionally, we present evidence to suggest a nuclear intracellular target for $\mathrm{Ca}$ Thi. Finally, our results show that FLC and CaThi combined causes dramatic morphological changes in these yeasts, effective against all 
Candida species tested. The combined treatment of $\mathrm{CaThi}$ and FLC is a strong candidate for clinical studies aiming to improve therapeutic results against resistant strains of Candida species. Studies involving drug combinations should be reinforced due to the possibility of synergistic effects that increase the toxic effect of the drugs combined when compared to monotherapy. Moreover, drug combinations can broaden the spectrum of antimicrobial activity, minimizing resistant microorganisms selection, increasing security and tolerance using lower drugs doses.

\section{Methods}

\section{Biological materials}

Capsicum annuum L. fruits (accession UENF1381) were provided by Laboratório de Melhoramento Genético Vegetal, from Centro de Ciências e Tecnologias Agropecuárias, Universidade Estadual do Norte Fluminense Darcy Ribeiro (UENF), Campos dos Goytacazes, Rio de Janeiro, Brazil.

The yeasts Candida albicans (CE022), Candida tropicalis (CE017), and Candida parapsilosis (CE002) were obtained from Departamento de Biologia, Universidade Federal do Ceará, Fortaleza, Brazil. The yeasts Candida pelliculosa (3974), Candida buinensis (3982), and Candida mogii (4674) were obtained from Micoteca URM from Universidade Federal de Pernambuco, Recife, Pernambuco, Brazil. Yeasts were maintained on Sabouraud agar (1 \% peptone, $2 \%$ glucose, and $1.7 \%$ agar-agar) (Merck) in the Laboratório de Fisiologia e Bioquímica de Microrganismos, from Centro de Biociência e Biotecnologia, UENF, Campos dos Goytacazes, Rio de Janeiro, Brazil.

\section{CaThi}

Extraction and purification of the thionin $\mathrm{CaThi}$ from Capsicum annuum fruits by chromatographic methods were performed as described by Taveira et al. [8]. The retention time to recover the thionin $\mathrm{CaThi}$ during the reversed-phase chromatography in column $\mu \mathrm{RPC} \mathrm{C}$ / C18 (ST 4.6/100) (GE Healthcare) was $37.87 \mathrm{~min}$.

\section{Preparation of yeast cells and determination of $\mathrm{IC}_{50}$ for CaThi and fluconazole}

For the preparation of yeast cell cultures, an inoculum from each stock of Candida albicans, Candida tropicalis, Candida parapsilosis, Candida pelliculosa, Candida buinensis, and Candida mogii was transferred to Petri dishes containing Sabouraud agar and allowed to grow at $30{ }^{\circ} \mathrm{C}$ for $48 \mathrm{~h}$. After this time, each cell aliquot was added to $10 \mathrm{~mL}$ sterile culture medium (Sabouraud broth, Merck). The cells were quantified in a Neubauer chamber (Optik Labor) with the aid of an optical microscope (Axiovison 4, Zeiss). The assay for checking the growth inhibition of yeast cells was performed according to Broekaert et al. [46] with modifications. Initially yeast cells $\left(1 \times 10^{4}\right.$ cells $\left.\mathrm{mL}^{-1}\right)$ were incubated in Sabouraud broth containing $\mathrm{CaThi}$ at concentrations ranging from $100 \mu \mathrm{g} \cdot \mathrm{mL}^{-1}$ to $1 \mu \mathrm{g} \cdot \mathrm{mL}^{-1}$ and fluconazole (FLC) at concentrations ranging from $20 \mu \mathrm{g} \cdot \mathrm{ml}^{-1}$ to $0.125 \mu \mathrm{g} \cdot \mathrm{mL}^{-1}$, with the final volume adjusted to $200 \mu \mathrm{L}$. The assay was performed in 96-well microplates (Nunc) at $30{ }^{\circ} \mathrm{C}$ for $24 \mathrm{~h}$. Optical readings at $620 \mathrm{~nm}$ were recorded at zero hour and every $6 \mathrm{~h}$ interval for $24 \mathrm{~h}$. Control cells were grown in the absence of CaThi and FLC. The optical densities were plotted against the concentration of $\mathrm{CaThi}$ and FLC, and then the concentration of the drug ( $\mathrm{CaThi}$ and $\mathrm{FLC})$ required for $50 \%$ inhibition $\left(\mathrm{IC}_{50}\right)$ in vitro of the tested yeasts was determined. Experiments were performed in triplicate.

\section{Viability assay}

To assay the effect of $\mathrm{CaThi}$ on the cell viability of yeasts, $1 \times 10^{4}$ cells $\mathrm{mL}^{-1}$ in Sabouraud broth culture medium and at the corresponding $\mathrm{IC}_{50}$ of $\mathrm{Ca}$ Thi values for each yeast were incubated at $30{ }^{\circ} \mathrm{C}$ for $24 \mathrm{~h}$ in 96 -well microplates (Nunc). To determine the control viability, the control cells (without $\mathrm{CaThi}$ ) were washed once and diluted 1,000-fold in Sabouraud broth culture medium, and an aliquot of $100 \mu \mathrm{L}$ from this dilution was spread over the surface of a Sabouraud agar medium (contained in a Petri dish) with a Drigalski loop and grown at $30^{\circ} \mathrm{C}$ for $48 \mathrm{~h}$. At the end of this period, colonies forming units (CFU) were determined for each yeast species, and the Petri dishes were photographed. The same procedure was followed with yeasts treated with $\mathrm{Ca}$ Thi. The experiments were carried out in triplicate, and the results are shown assuming that the control represents $100 \%$ viability. Calculations of the standard deviation and $T$ test were performed with Prism software (version 5.0).

\section{Plasma membrane permeabilization assay}

The plasma membrane permeabilization of yeast cells was measured by Sytox green uptake, according to the methodology described by Thevissen et al. [47], with some modifications. Each of the different species of yeasts was incubated with $\mathrm{CaThi}$ at the concentration required to inhibit $50 \%$ growth $\left(\mathrm{IC}_{50}\right)$ of the respective yeast cells for $24 \mathrm{~h}$. After this time, a $100 \mu \mathrm{L}$ aliquot of each yeast cell suspension was incubated with $0.2 \mu \mathrm{M}$ of Sytox green in $1.5 \mathrm{~mL}$ microcentrifuge tubes for $30 \mathrm{~min}$ at $25{ }^{\circ} \mathrm{C}$ with constant agitation. Cells were analyzed by DIC optical microscope (Axiovison 4, Zeiss) equipped with a fluorescent filter set for detection of the fluorescein (excitation wavelength, $450-490 \mathrm{~nm}$, emission wavelength $500 \mathrm{~nm}$ ). To indicate membrane permeabilization, the percentage of fluorescent cells was determined by counting the DIC and fluorescent views 
for each yeast $(n=5)$. The total cell number in DIC view of each yeast (in control and test) was assumed as $100 \%$. The experiments were carried out in triplicate. Calculations of $T$ test were performed with Prism software (version 5.0).

\section{Determining the induction of intracellular ROS in yeast cells}

To evaluate whether the mechanism of action of $\mathrm{CaThi}$ involves induction of oxidative stress, the fluorescent probe 2,7 -dichlorofluorescein diacetate $\left(\mathrm{H}_{2}\right.$ DCFDA) was used to measure intracellular reactive oxygen species (ROS) according to the methodology described by Mello et al. [31]. Each of the different species of yeasts was incubated with the respective $\mathrm{IC}_{50}$ for $\mathrm{CaThi}$ in 96-well microplates for $24 \mathrm{~h}$ at $30{ }^{\circ} \mathrm{C}$; after this incubation an aliquot of $50 \mu \mathrm{L}$ of each of yeast cell suspension was incubated with $200 \mu \mathrm{M}$ of $\mathrm{H}_{2}$ DCFDA in micro centrifuge tubes of $1.5 \mathrm{~mL}$ for $1 \mathrm{~h}$ at $25^{\circ} \mathrm{C}$ with constant agitation at $500 \mathrm{rpm}$. Cells were analyzed by DIC optical microscope (Axiovison 4, Zeiss) equipped with a fluorescent filter set for detection of the fluorescein (excitation wavelength, $450-490 \mathrm{~nm}$, emission wavelength $500 \mathrm{~nm}$ ). The experiments were carried out in triplicate.

\section{CaThi conjugated to FITC localization for optical microscopy}

$\mathrm{CaThi}$ at $100 \mu \mathrm{g}$ was resuspended in $100 \mu \mathrm{L}$ of $750 \mathrm{mM}$ sodium carbonate-sodium bicarbonate buffer, $\mathrm{pH} 9.5$ containing FITC at $50 \mu \mathrm{g} \cdot \mathrm{mL}^{-1}$ (previously solubilized in DMSO). This solution was incubated with constant agitation at $500 \mathrm{rpm}$ for $2 \mathrm{~h}$ at $30^{\circ} \mathrm{C}$. After this incubation, the sample was submitted to gel filtration chromatography on Sephadex G25 column (Sigma) for elimination of free FITC and recovery CaThi-FITC. The column was equilibrated and run with $20 \mathrm{mM}$ Tris$\mathrm{HCl}, \mathrm{pH} 8.0$ at flow rate of $0.3 \mathrm{~mL} \cdot \mathrm{mim}^{-1}$. After coupling, $10 \mu \mathrm{g} \cdot \mathrm{mL}^{-1}$ of $\mathrm{Ca}$ Thi-FITC was incubated with cells of C. albicans and C. tropicalis for $24 \mathrm{~h}$ in 96-well microplates. After this time an aliquot of each cell suspension was removed and incubated with $50 \mu \mathrm{g} \cdot \mathrm{mL}^{-1}$ of 4 ,6-diamidino-2-phenylindole dihydrochloride (DAPI) for $10 \mathrm{~min}$ for nuclei stain. Cells were analyzed by DIC optical microscope (Axiovison 4, Zeiss) equipped with a fluorescent filter set for detection of the fluorescein (excitation wavelength, 450-490 nm, emission wavelength $500 \mathrm{~nm}$ ). The entire assay was performed protected from light.

\section{Synergism assay}

To verify the synergistic activities, we combined FLC with $C a$ Thi. Initially yeast cells $\left(1 \times 10^{4}\right.$ cells $\left.\mathrm{mL}^{-1}\right)$ were incubated in Sabouraud broth containing an $\mathrm{IC}_{50}$ concentration or less than that for FLC and $\mathrm{CaThi}$ concentrations ranging from 1.3 to 4.0 times below the $\mathrm{IC}_{50}$ for the respective yeast and the final volume adjusted to $200 \mu \mathrm{L}$ in vitro. The assay was performed in 96-well microplates (Nunc) at $30^{\circ} \mathrm{C}$ for $24 \mathrm{~h}$. Optical readings at $620 \mathrm{~nm}$ were taken at zero hour and every $6 \mathrm{~h}$ for the following $24 \mathrm{~h}$. Control cells were: 1 ) grown in the absence of $\mathrm{CaThi}$ and FLC; 2) grown in the presence of FLC; 3) grown in the presence of CaThi. The synergistic activity was deduced comparing optical densities of each control and combined drugs (FLC plus $\mathrm{CaThi}$ ) considering each yeast strain tested. We define synergism as the combination action of the AMP with other substance that causes an enhanced decrease in the growth of the microorganism, compared with the growth inhibition of the single substances. After synergism, assay cells (controls and tests) were analyzed by DIC optical microscope (Axiovison 4, Zeiss). The data were obtained from experiments performed in triplicate. The data were evaluated using a one-way ANOVA. Mean differences at $p<0.05$ were considered to be significant. All statistical analyses were performed using the GraphPad Prism software (version 5.0 for Windows).

\section{Scanning electron microscopy}

C. pelliculosa and C. buinensis cells were submitted to scanning electron microscopy (SEM) analysis. Yeast cells were grown for $24 \mathrm{~h}$ in Sabouraud broth in the presence of FLC (5 $\mu \mathrm{g} \cdot \mathrm{mL}^{-1}$ and $0.125 \mu \mathrm{g} \cdot \mathrm{mL}^{-1}$, respectively), CaThi $\left(40 \mu \mathrm{g} \cdot \mathrm{mL}^{-1}\right.$ and $10 \mu \mathrm{g} \cdot \mathrm{mL}^{-1}$, respectively), and FLC plus CaThi $\left(2.5 \mu\right.$ g.mL $\mathrm{mL}^{-1}+15 \mu \mathrm{g} \cdot \mathrm{mL}^{-1}$, $0.06 \mu \mathrm{g} \cdot \mathrm{mL}^{-1}+5 \mu \mathrm{g} \cdot \mathrm{mL}^{-1}$, respectively) or absence of these drugs, then were fixed for $30 \mathrm{~min}$ at $30{ }^{\circ} \mathrm{C}$ in a solution containing $2.5 \%$ glutaraldehyde and $4.0 \%$ formaldehyde in $0.1 \mathrm{M}$ cacodylate buffer, $\mathrm{pH}$ 7.0. Subsequently, the cells were rinsed three times in $0.1 \mathrm{M}$ cacodylate buffer, $\mathrm{pH}$ 7.0; post-fixed for $30 \mathrm{~min}$ at $30{ }^{\circ} \mathrm{C}$ with $1.0 \%$ osmium tetroxide diluted in $0.1 \mathrm{M}$ cacodylate buffer, $\mathrm{pH}$ 7.0; and rinsed again with this same buffer. The yeast cells were gradually dehydrated in alcohol solution $(15,30,50,70$ to $90 \%$ and finally $100 \%$ alcohol), critical point dried in $\mathrm{CO}_{2}$, covered with $20 \mathrm{~nm}$ gold and observed in a DSEM 962 Zeiss SEM.

\section{Abbreviations}

AMP: Antimicrobial peptide; FLC: Fluconazole; ROS: Reactive oxygen species; CaThi: Capsicum annuum Thionin; DIC: Differential interference contrast;

FITC: Fluorescein isothiocyanate; SEM: Scanning Electron Microscopy.

\section{Competing interests}

The authors declare that they have no competing interests.

\section{Authors' contributions}

Conceived and designed the experiments: GBT, AOC, RR, FGT, MC and VMG. Performed the experiments: GBT and FGT. Analyzed the data: GBT, AOC, FGT, $M C$ and VMG. Contributed reagents/materials/analysis tools: AOC, RR, MC 
and VMG. Wrote the paper: GBT, AOC and VMG. All authors read and approved the final manuscript.

\section{Acknowledgments}

This study forms part of the DSc degree thesis of GBT, carried out at the Universidade Estadual do Norte Fluminense Darcy Ribeiro. We acknowledge the financial support of the Brazilian agencies CNPq, FAPERJ, and CAPES through the CAPES/Toxinology project. We wish to thank L.C.D. Souza and V.M. Kokis for technical assistance.

\section{Author details}

'Laboratório de Fisiologia e Bioquímica de Microrganismos, Centro de Biociências e Biotecnologia, Universidade Estadual do Norte Fluminense, Campos dos Goytacazes 28013-602, RJ, Brazil. Laboratório de Melhoramento Genético Vegetal, Centro de Ciências e Tecnologias Agropecuárias, Universidade Estadual do Norte Fluminense, Campos dos Goytacazes 28013-602, RJ, Brazil. ² Laboratório de Biologia Celular e Tecidual, Centro de Biociências e Biotecnologia, Universidade Estadual do Norte Fluminense, Campos dos Goytacazes 28013-602, RJ, Brazil.

\section{Received: 8 July 2015 Accepted: 14 January 2016}

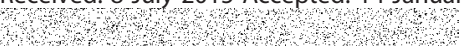

\section{References}

1. Pappas PG. The role of azoles in the treatment of invasive mycoses: review of the Infectious Diseases Society of America guidelines. Curr Opin Infect Dis. 2011;24 Suppl 2:S1-S13.

2. Avent ML, Rogers BA, Cheng AC, Paterson DL. Current use of aminoglycosides: indications, pharmacokinetics and monitoring for toxicity. Intern Med J. 2001:41:441-9.

3. Zasloff M. Antimicrobial peptides of multicellular organisms. Nature. 2002; 415:389-95.

4. Guaní-Guerra E, Santos-Mendoza T, Lugo-Reyes SO, Terán LM. Antimicrobial peptides: General overview and clinical implications in human health and disease. Clinical Immunol. 2010;135:1-11.

5. Carvalho AO, Gomes VM. Plant defensins and defensin-like peptides biological activities and biotechnological applications. Curr Pharm Des. 2011;17(38):4270-93.

6. Castro MS, Fontes W. Plant defense and antimicrobial peptides. Protein Pept Lett. 2005;12(1):13-8

7. Kido EA, Pandolfi V, Houllou-Kido LM, Andrade PP, Marcelino FC, Nepomuceno AL, et al. Plant Antimicrobial Peptides: An overview of superSAGE transcriptional profile and a functional review. Curr Protein Pept Sci. 2010;11:220-30.

8. Taveira GB, Mathias LS, Vieira-da-Motta O, Machado OLT, Rodrigues R, Carvalho AO, et al. Thionin-like peptides from Capsicum annuum fruits with high activity against human pathogenic bacteria and yeasts. Biopolymers. 2014;102:30-9.

9. Lee SC, Hong JK, Kim YJ, Hwang BK. Pepper gene enconding thionin is differentially induced by pathogens, ethilene and methyl jasmonete. Phisiol Mol Plant Pathol. 2000;56:207-16.

10. Stec B. Plant thionins - the structural perspective. Cell Mol Life Sci. 2006;63: 1370-85.

11. Silva S, Negri M, Henriques M, Oliveira R, Williams DW, Azeredo J. Candida glabrata, Candida parapsilosis and Candida tropicalis: biology, epidemiology, pathogenicity and antifungal resistance. FEMS Microbiol Ver. 2012; 36:288-305.

12. Krcmery V, Barner AJ. Non-albicans Candida spp. causing fungaemia: pathogenicity and antifungal resistance. J Hosp Infect. 2002:4:243-60.

13. Sanglard D. Resistance of human fungal pathogens to antifungal drugs. Curr Opin Microbiol. 2002:5:379-85.

14. Cannon RD, Lamping E, Holmes AR, Niimi K, Baret PV, Keniya MV, et al. Efflux-mediated antifungal drug resistance. Clin Microbiol Rev. 2009;22(2): 291-321.

15. Iwazaki RS, Endo EH, Ueda-Nakamura T, Nakamura CV, Garcia LB, Filho BP. In vitro antifungal activity of the berberine and its synergism with fluconazole. Antonie Van Leeuwenhoek. 2010;97:201-5.

16. Barbosa FM, Daffre S, Maldonado RA, Miranda A, Nimrichter L, Rodrigues ML. Gomesin, a peptide produced by the spider Acanthoscurria gomesiana is a potent anticryptococcal agent that acts in synergism with fluconazole. FEMS Microbiol Lett. 2007;274(2):279-86.
17. Rossi DC, Muñoz JE, Carvalho DD, Belmonte R, Faintuch B, Borelli P, et al. Therapeutic use of a cationic antimicrobial peptide from the spider Acanthoscurria gomesiana in the control of experimental candidiasis. BMC Microbiology. 2012;12:28.

18. Giudici AM, Regente MC, Villalaín J, Pfüller K, Pfüller U, De La Canal L. Mistletoe viscotoxins induce membrane permeabilization and spore death in phytopathogenic fungi. Physiol Plantarum. 2004;121:2-7.

19. Molina A, Ahl Goy P, Fraile A, Sfinchez-Monge R, Garcia-Olmedo F. Inhibition of bacterial and fungal plant pathogens by thionins of types I and II. Plant Sci. 1993;92:169-77.

20. Chandrashekhara NRS, Deepak S, Manjunath G, Shetty SH. Thionins (PR protein-13) mediate pearl millet downy mildew disease resistance. Arch Phytopathol Plant Protect. 2010:48(14):1356-66.

21. García-Olmedo F, Molina A, Alamillo JM, Rodríguez-Palenzuéla P. Plant Defense Peptides. Pept Sci. 1998:47:479-91.

22. Ganz T, Lehrer RI. Antibiotic peptides from higher eukaryotes: biology and applications. Mol Med Today. 1999:5:292-7.

23. Bera A, Singh S, Nagaraj R, Vaidya T. Induction of autophagic cell death in Leishmania donovani by antimicrobial peptides. Mol Biochem Parasitol. 2003;127:23-35

24. Vylkova S, Nayyar N, Li W, Edgerton M. Human -Defensins Kill Candida albicans in an Energy-Dependent and Salt-Sensitive Manner without Causing Membrane Disruption. Antimicrob Agents Chemother. 2007;51(1):154-61.

25. Loeza-Ángeles H, Sagrero-Cisneros E, Lara-Zárate L, Villagómez-Gómez E, López-Meza JE, Ochoa-Zarzosa A. Thionin Thi2.1 from Arabidopsis thaliana expressed in endothelial cells shows antibacterial, antifungal and cytotoxic activity. Biotechnol Lett. 2008;30:1713-19.

26. Thevissen K, Ghazi A, De Samblanx GW, Brownlee C, Osborn RW, Broekaert WF. Fungal membrane responses induced by plant defensins and thionins. J Biol Chem. 1996:271:15018-25.

27. Giudici M, Poveda JA, Molina ML, De La Canal L, González-Ros JM. Antifungal effects and mechanism of action of viscotoxin A3. FEBS Journal. 2006;273:72-83

28. Dathe M, Meyer J, Beyermann M, Maul B, Hoischen C, Bienert M. General aspects of peptide selectivity towards lipid bilayers and cell membranes studied by variation of the structural parameters of amphipathic helical model peptides. Biochim Biophys Acta. 2002;1558:171-86.

29. Addabbo F, Montagnani M, Goligorsky MS. Mitochondria and Reactive Oxygen Species. Hypertension. 2009;53:885-92.

30. Aerts AM, François IEJA, Meert EMK, Li QT, Cammue BPA, Thevissen K. The antifungal activity of Rs-AFP2, a plant defensin from Raphanus sativus, involves the induction of reactive oxygen species in Candida albicans. Mol Microbiol Biotechnol. 2007:13:243-47.

31. Mello EO, Ribeiro SFF, Carvalho AO, Santos IS, Da Cunha M, Santa Catarina C, et al. The antifungal activity of PVD1, a plant seed defensin of Phaseolus vulgaris, involves plasma membrane permeabilization, inhibition of medium acidification and induction of reactive oxygen species in yeast cells. Curr Microbiol. 2011;62:1209-17

32. Hwang B, Hwang J-S, Lee J, Lee DG. The antimicrobial peptide, psacotheasin induces reactive oxygen species and triggers apoptosis in Candida albicans. Biochem Biophys Res Commun. 2011:405:267-71.

33. Brogden KA. Antimicrobial peptides: pore formers or metabolic inhibitors in bacteria? Nat Rev Microbiol. 2005;3:238-50.

34. Nicolas P. Multifunctional host defense peptides: intracellular-targeting antimicrobial peptides. FEBS J. 2009;276:6483-96.

35. Matsuzaki K, Sugishita K, Harada M, Fujii N, Miyajima K. Interactions of an antimicrobial peptide, magainin 2, with outer and inner membranes of Gram-negative bacteria. Biochim Biophys Acta. 1997;1327:119-30.

36. Franco OL. Peptide promiscuity: An evolutionary concept for plant defense. FEBS Letters. 2011:585:995-1000.

37. Carvalho AO, Gomes VM. Plant defensins - prospects for the biological functions and biotechnological properties. Peptides. 2009:30:1007-20.

38. Yonezawa A, Kuwahara J, Fujii N, Sugiura Y. Binding of tachyplesin I to DNA revealed by footprinting analysis: significant contribution of secondary structure to DNA binding and implication for biological action. Biochemistry. 1992;31:2998-3004.

39. Boman HG, Agerberth B, Boman A. Mechanisms of action on Escherichia coll of cecropin-P1 and PR-39, 2 antibacterial peptides from pig intestine. Infect Immun. 1993:61:2978-84

40. Helmerhorst EJ, Breeuwer P, van t Hof W, Walgreen-Weterings E, Oomeni LCJM, Veerman ECl, et al. The Cellular Target of Histatin 5 on Candida albicans Is the Energized Mitochondrion. J Biol Chem. 1999;274(11):7286-91. 
41. Vieira MEB, Vasconcelos IM, Machado OLT, Gomes VM, Carvalho AO. Isolation, characterization and mechanism of action of an antimicrobial peptide from Lecythis pisonis seeds with inhibitory activity against Candida albicans. Acta Biochim Biophys Sin. 2015:47(9):716-29.

42. Kulkarni MM, McMaster RW, Kamysz W, McGwire BS. Antimicrobial Peptideinduced Apoptotic Death of Leishmania Results from Calcium-dependent, Caspase-independent Mitochondrial Toxicity. J Biol Chem. 2009;284(23): 15496-504.

43. Aerts AM, Carmona-Gutierrez D, Lefevre S, Govaert G, Francois IE, Madeo F, et al. The antifungal plant defensin RsAFP2 from radish induces apoptosis in a metacaspase independent way in Candida albicans. FEBS Lett. 2009;583: 2513-16.

44. Lupetti A, Danesi R, Campa M, Del Tacca M, Kelly S. Molecular basis of resistance to azole antifungals. Trends Mol Med. 2002;8:76-81.

45. Cowen LE. The evolution of fungal drug resistance: modulating the trajectory from genotype to phenotype. Nat Rev Microbiol. 2008;6:187-98.

46. Broekaert WF, Mariën W, Terras FR, De Bolle MF, Proost P, Van Damme J, et al. Antimicrobial peptides from Amaranthus caudatus seeds with sequence homology to the cysteine/glycine rich domain of chitin-binding proteins. Biochemistry. 1992;31:4308-14.

47. Thevissen K, Terras FRG, Broekaert WF. Permeabilization of fungal membranes by plant defensins inhibits fungal growth. Appl Environ Microbiol. 1999;65:5451-58.

\section{Submit your next manuscript to BioMed Central and we will help you at every step:}

- We accept pre-submission inquiries

- Our selector tool helps you to find the most relevant journal

- We provide round the clock customer support

- Convenient online submission

- Thorough peer review

- Inclusion in PubMed and all major indexing services

- Maximum visibility for your research

Submit your manuscript at www.biomedcentral.com/submit

) Biomed Central 